\title{
Addressing the Psychosocial Needs of Pregnant Women Affected by War: Program Approaches and Program Gaps
}

\author{
Bree Akesson
}

\section{Abstract}

Today's female refugee and internally displaced population faces the increasing risk of adverse birth outcomes associated with stress related to conflict, flight, and displacement. Programs addressing the specific psychosocial needs of pregnant women in situations of war are scarce, and there is little consensus regarding best practices. Initiatives have recently emerged, including psychosocial groups, safe motherhood training, and social support systems, all which aim to alleviate the psychosocial stress experienced by this cohort. However, there remain existing program gaps, such as the absence of specific quality research, the use of a deficits-based vernacular concentrated on vulnerabilities, no focus on postpartum care, and little development of gender-based violence prevention initiatives addressing pregnancies resulting from rape. It is clear that more needs to be done to provide and support comprehensive quality psychosocial services for this population.

\section{Résumé}

De nos jours les femmes réfugiées et les populations déplacées à l'intérieur des frontières font face à un risque croissant d'accouchements à problèmes résultant du stress lié aux conflits, à la fuite, et au déplacement. Les programmes pour satisfaire les besoins psychosociaux spécifiques de femmes enceintes dans les situations de guerre sont rares, et il y a peu de consensus en matière de meilleures pratiques. Des initiatives sont apparues récemment, y compris l'émergence de groupes psychosociaux, de la formation pour une maternité sans risque, et des systèmes de support sociaux, qui visent tous à alléger le stress psychosocial éprouvé par toutes celles concernées. Cependant ces programmes comportent encore des lacunes, telles que l'absence de recherche spécifique de bonne qualité, l'utilisation d'un vernaculaire fondé sur les déficiences et se concentrant sur les vulnérabilités, le manque de considération pour les soins suivant l'accouchement, et peu de développement dans les initiatives concernant la prévention de la violence liée au sexe et traitant des grossesses résultant du viol. Il est clair que davantage doit être fait pour fournir et soutenir des services psychosociaux complets et de qualité pour cette population.

7 raditionally, relief efforts during complex emergencies have focused on the provision of food, water, shelter, and health care, with the overarching goal of reducing morbidity and mortality. Gender-specific needs of women are often compromised during wartime, especially the mental health needs of pregnant women. This article focuses on the current program approaches and gaps that exist in addressing pregnant women's mental health needs during times of war and suggests hopeful theoretical methods for the development and improvement of future programs.

Individuals affected by war experience fluctuations in violence, displacement to unfamiliar surroundings, disruption of family and community structures, and lack of access to basic needs. Although many war-affected individuals may experience physical and emotional stress associated with conflict, flight, and displacement, pregnant women may suffer from this stress differently, as they find themselves struggling to meet their families' survival needs while attempting to meet their own physical needs. For the 
trauma of war is not related just to the exposure to violence, but also to the hardships associated with increased poverty, loss of place, and disintegration of social structures.

Of the estimated 9.2 million refugees and 25 million internally displaced people in the world today, 80 per cent are women or children. ${ }^{1}$ Among refugee populations, approximately 25 per cent are women of reproductive age, with one in five of these women likely to become pregnant at any time during the course of conflict, flight, or displacement. ${ }^{2}$ Fifteen per cent of pregnant women will experience complications during pregnancy or delivery which require emergency obstetric care. ${ }^{3}$ Globally, complications from pregnancy and childbirth are the leading cause of death and disability for women aged fifteen to forty-nine in most developing countries. ${ }^{4}$ During conflict, flight, and displacement, childbirth may occur at any place and at any time, without adequate preparation for the culturally salient practices that are often intrinsic pieces of traditional childbirth processes. For example, with approximately 200,000 Sudanese refugees crossing the Sudan-Chad border since early 2004, women have been forced to give birth while in transit to camps for internally displaced persons (IDPs) or refugees without the presence of a skilled birth attendant, without access to the basic items for a safe and clean delivery, and with the unfortunate consequence of an unnecessarily high maternal morbidity rate. ${ }^{5}$ In developing countries, only 53 percent of deliveries are attended by a skilled health care worker, with emergency conditions allowing access to skilled attendants and safe delivery kits even less likely. ${ }^{6}$

The psychosocial implications for pregnant women in situations of complex emergencies are extremely important, as numerous studies depict this association between maternal mental health and birth outcomes. Researchers in Belgium cite evidence that anxiety experienced by pregnant women between weeks 12 and 22 of pregnancy had a significant effect on certain childhood behavioural problems manifested in their offspring. ${ }^{7}$ According to the United National Population Fund (UNFPA), stress from war leads to an increased number of miscarriages among pregnant women. ${ }^{8}$ A study in Chile looking at the relationship between pregnancy complications and protracted sociopolitical violence in Santiago from 1985 to 1986 found that female residents from Santiago's urban neighbourhoods with high levels of violence were five times more likely to experience pregnancy complications than those who lived in neighbourhoods with low levels of violence. ${ }^{9}$

It is pertinent to consider rape as a means whereby women may become pregnant in situations of war. Although most instances of pregnancy are likely to be the result of a consensual sexual act, rape during wartime is also a reality. It is difficult to quantify the magnitude of wartime rape, since accurate statistics are difficult to obtain using traditional public health methodologies. However, it is known that wartime rape is often widespread, used as a means to disable a population by humiliating, dominating, or disrupting the social ties of family and community. ${ }^{10}$ In certain conflicts such as Bosnia, Rwanda, and Sudan, certain ethnic populations have been targeted for sexual violence. Specifically, in the former Yugoslavia, rape was used as a means of "ethnic cleansing through impregnation." 11 Rape survivors do not just face the physical manifestations of the act, but may also face social exclusion and isolation from their families and communities. And since pregnancy may result from rape, mental health issues such as anxiety, post-traumatic stress disorder, and depression should specifically be addressed among this cohort of pregnant women.

\section{Program Approaches}

As noted above, psychosocial programs specifically for pregnant women in situations of complex emergencies are scarce. Thus, there is little experience and few lessons on which to base best practices. The following highlights some approaches which have been undertaken in the field of humanitarian aid. Threaded throughout as a contextual example of an existing and evolving initiative that addresses the psychosocial needs of pregnant women is the International Rescue Committee's public health program in the Northern Caucasus. Since the war in the Northern Caucasus is considered more protracted than acute in nature, it should be noted that these programs may be easier to do in this context. Therefore we know even less about how to actually implement these activities in acute crisis settings.

\section{Psychosocial Groups}

The premise of psychosocial groups is to provide a forum for pregnant women to give and receive support with the end goal of improving mental health. Psychosocial groups can be informational, educating the pregnant women about pregnancy, or they can address psychological issues that are especially important within the stress of war. Pregnancy is an opportune time for psychosocial intervention, because the woman is receptive to learning how to care for herself and her baby. This is also a time when the community may be more willing to devote resources to the pregnant woman, because the community may believe it is an investment in both the woman and child. Since pregnancy can often be a stressful period, with significant physiological and social changes, any program that can reduce this stress is helpful for the mother and child.

The International Rescue Committee's public health program in the Northern Caucasus conducts psychosocial 
groups for pregnant women in war-torn Chechnya and the neighbouring Republic of Ingushetia. Each participant receives two hours of group counselling and education about psychosocial disturbances and the effects on the fetus and infant, as well as on the mother's overall health. Participants in the program found these groups to be especially helpful in the context of the Chechen conflict, as they offered a safe and consistent forum within which to discuss mental health issues.

\section{Safe Motherhood Training}

Safe motherhood means ensuring that women receive the care and assistance they need to be safe and healthy throughout pregnancy and childbirth. The utilization of safe motherhood kits (i.e., sterile delivery kits, hygiene promotion kits) is an essential component of a safe delivery. Furthermore, traditional birth attendants and midwives often have an important role in the promotion of maternal mental well-being. Most importantly, for programs to be effective, pregnant women must have access to safe motherhood services, including adequate supplies, transportation to facilities, and contact with trained staff who can address emergency obstetric care.

In the Northern Caucasus, the International Rescue Committee's Safe Motherhood Program involves 576 young and pregnant mothers in schools in the Chechen capital of Grozny. Pregnant women meet in groups of twelve every week for one month to learn and discuss safe motherhood issues with local medical professionals, who facilitate the trainings. Participants receive medical information and safe motherhood kits, which they say help alleviate the stress of pregnancy. Participants in the program have said that preparing for childbirth is an anxietyrelieving activity, and that the knowledge they have gained from participation in the group helps to allay fears that may already be heightened as a result of the Chechen conflict.

\section{Social Support Systems}

War does not occur in isolation; rather it compounds the difficulties that the war-affected individuals normally face and overloads existing resources. As war becomes protracted, both the individual and the community have fewer resources to draw upon. ${ }^{12}$ In this context, support systems become especially important as social capital. Furthermore, there is general consensus that social supports moderate stress and its negative health consequences. ${ }^{13}$

Dalianis-Karambatzakis describes the support systems that were available for pregnant women during the Greek Civil War in the late 1940s. ${ }^{14}$ Many of the women documented in the study were imprisoned and the support programs were self-devised. They included sharing child care, tutoring illiterate mothers, and redistributing limited food supplies to those mothers and infants who were most needy. Almedon et al.'s study of maternal psychosocial well-being notes the elaborate support systems established in Eritrea, where pregnant women are provided special care and support during pregnancy, childbirth, and beyond. ${ }^{15}$ Many ethnic groups in Eritrea still uphold the practice of postpartum seclusion and rest for mothers who have just given birth and exempt them from any work other than breastfeeding. The community comes forward to help with domestic tasks, ensuring that the new mother is well taken care of. War, however, limits these women's ability to partake in particular customs because of a lack of resources and a disruption of community.

The idea of social support can also be exemplified from the wider macrosystems perspective with many governmental and non-governmental agencies' efforts at relocation and resettlement. In complex emergencies, transportation is often provided primarily for the vulnerable (i.e., pregnant and nursing women, children, the sick, and elderly), while able people leave on foot. Efforts have been made to maintain pre-existing social ties, especially in regard to pregnant women, who need the support of their families and communities. For example, in Eritrea, humanitarian agencies made efforts to allow villages to remain together as community structures, rather than being separated into categories of perceived vulnerability. ${ }^{16}$ In this way, anxiety was relieved, as existing social supports were preserved throughout the displacement and resettlement process.

\section{Program Gaps}

\section{Research}

Relief agencies' response to refugees' needs have been hampered by a dearth of research and program experience. There is a great need for studies pointing to best practices for psychosocial programs, as well as research regarding the mental health needs of specific cohorts of refugees, especially pregnant women. Though there is evidence that stress during pregnancy leads to an increase in pregnancy complications, studies examining this relationship in the context of war are necessary.

\section{Strengths-based Vernacular}

There is an emphasis on deficits-focused vernacular rather than a strengths-based approach. For example, pregnant women are often categorized as "vulnerable," whereas many of them possess individual and collective resilience, resourcefulness, and strength, especially in the face of war. In the instance of young mothers among fighting forces, young women are often perceived as victims of sexual violence and abuse. However, there has been evidence that, in many cases, 
girls have made choices to become pregnant in the face of other more dangerous options such as being forced to have multiple sexual partners or to fight in conflict. ${ }^{17}$ In other words, these women's "choice," albeit a survival mechanism, was made as a means of self-preservation. One must not disregard agency and perseverance as concepts at work amongst populations such as this.

\section{Equal Emphasis on Postpartum Period}

There is evidence that postnatal depression affects child outcomes. The World Health Organization reports that worldwide incidence of severe postpartum depression is about 6 per cent. ${ }^{18}$ Studies indicate that the postnatal environment is an important predictor of infant development, with infants who interact with depressed mothers at greater risk for later behavioural problems. ${ }^{19}$ Another study from India shows that a mother's depression negatively impacts infant development. ${ }^{20}$ When applying this evidence to the complex emergency model, the impact of maternal mental health may be even greater during times of war when there may be additional stress factors influencing the mother. It is clear that maternal psychosocial well-being is an important determinant of infant health in situations of war. Effective programs must address the postnatal period to assess for maternal mental health and its impact on existing children.

\section{Awareness of Pregnancies Resulting from Rape}

During situations of complex emergencies, rape survivors do not always receive medical attention due to a lack of attention to gender-based violence and limited genderbased violence programs. ${ }^{21}$ The field of humanitarian assistance needs an increase in awareness about gender-based violence in complex emergencies, the creating and enforcement of established protocols for treating individuals affected by gender-based violence, and the fortification of programs across all sectors to prevent and respond to future acts of gender-based violence. For, in order to address pregnancies resulting from rape, there must be adequate program attention.

\section{Future Programs}

While most programs in complex emergencies focus on concrete and direct ways to reduce morbidity and mortality (i.e., water and sanitation, immunizations, nutrition, etc.), the field of humanitarian aid must carve out a place for mental health interventions, acknowledging that the alleviation of psychological suffering should also be attended to in the early stages of emergencies. Jacobson notes that the presence of social support curbs stress and anxiety and their resulting health consequences. ${ }^{22}$ Per Jacobson, there are three types of social support, which fit into the context of meeting pregnant women's needs in complex emergencies: emotional support, cognitive support, and materials support. $^{23}$

Emotional support is "behavior that fosters feelings of comfort and leads an individual to believe that...others are available to provide caring and security." ${ }^{24}$ Oftentimes, a pregnant woman relies on her family and community for this kind of emotional support. In Eritrea, many believed that being connected to their own community and the country as a whole served as a protective factor against chinquet (mental oppression). ${ }^{25}$ From this perspective, programs must include a family systems approach, including all members of the family in the care of the pregnant woman.

Jacobson defines cognitive support as "information, knowledge, and/or advice that helps the individual to understand his or her world and to adjust to changes within it."26 Material support includes "the goods and services that help to solve practical problems." ${ }^{27}$ The implementation of psychosocial groups, with the provision of safe motherhood kits, allows for the development of a stable environment in an otherwise unstable world. However, cognitive support should continue through the postpartum period, with the provision of information such as caring for the newborn and recognizing signs of postpartum depression. Program developers should remember that the mental well-being and morale of mothers with infants and young children and their families needs to be attended to throughout complex emergencies.

In situations of war, programs often need to be implemented quickly in order to mitigate war's negative consequences effectively. With conditions oftentimes deteriorating, research is often difficult to carry out. Large amounts of money are spent on aid programs, and for economical as well as ethical reasons, it is important to know what works best, when, and for whom. In spite of the many obstacles confronted in war situations, analyzing experiences and data to determine best practices is needed. To carry out this work, consultation with those familiar with the health needs, the local culture, and the security situation is necessary to approach the research from a multidisciplinary perspective and to enable the effective facilitation of this work. ${ }^{28}$

Psychosocial programs must include a comprehensive strategy for addressing the needs of pregnant women in complex emergencies. Service providers must strive to create an environment of support as well as access to adequate safe motherhood information to assuage stress in an already stressful environment. With the support of donors, the international community may be able to take a more significant role in addressing the needs of this population. However, because of the general dearth of research and few programs that address psychosocial needs in situations of war, it is clear 
that much more needs to be done to provide and support comprehensive quality psychosocial services. For the failure to address the needs of populations affected by crisis undermines the stability of nations and stalls prospects of post-conflict resolution, restoration, and development.

\section{Notes}

1. UNFPA, The state of world population, 2000, $<$ http://www.unfpa.org/swp/2000/english/> (accessed January 14, 2006); UNHCR, Refugees by numbers [A5 brochure], 2005, <http://www.unhcr.org/cgibin/texis/vtx/basics/opendoc.pdf?id=416e3eb24\&tbl=BASICS\&page $=$ basics $>($ accessed January 14, 2006).

2. UNHCR, Reproductive health in refugee situations: an interagency field manual, 1999, <http://www.unhcr.ch/cgi-bin/ texis/vtx/publ/opendoc.pdf?tbl=PUBL\&id=3bc6ed6fa $>($ accessed January 14, 2005).

3. S. K. Krause, R. K. Jones, and S. J. Purdin, "Programmatic Responses to Refugees' Reproductive Health Needs," International Family Planning Perspectives 26, no. 4 (December 2000): 181-187; UNHCR.

4. UNFPA, Sudan:UNFPA prescribes a new lease on health and life for Kalma's mothers and newborns [News Feature] July 22, 2005, <http://www.unfpa.org/news/news.cfm?ID= 652\&Language $=1>($ accessed January 16, 2006).

5. Women's Commission for Refugee Women and Children, "Don't forget us": The education and gender-based violence protection needs of adolescent girls from Darfur and Chad [Report], July 2005, <http://www.womenscommission. org/pdf/Td_ed2.pdf?alertid $=8285226 \&$ type $=C O>$ (accessed January 16, 2006).

6. UNFPA, "Sudan: UNFPA prescribes a new lease on health and life for Kalma's mothers and newborns."

7. Bea RH. Van den Bergh and Alfons Marcoen, "High Antenatal Maternal Anxiety Is Related to ADHD Symptoms, Externalizing Problems, and Anxiety in 8-and 9-Year-Olds," Child Development 75, no. 4 (2004): 1085-1097, doi:10.1111/j.14678624-2004.00727.x.

8. UNFPA, "Sudan: UNFPA prescribes a new lease on health and life for Kalma's mothers and newborns."

9. T. McGinn, "Reproductive Health of War-Affected Populations: What Do We Know?" International Family Planning Perspectives 26, no. 4 (December 2000): 74-180.

10. UNFPA, Women's empowerment and reproductive health: reproductive health and violence, 2006, <http://www.unfpa. org/intercenter/cycle/violence.htm $>$ (accessed January 17, 2006).

11. C. Watts and C. Zimmerman, "Violence against Women: Global Scope and Magnitude (The Lancet 359 (April 6, 2002): 1236.

12. J. W. Bryce, N. Walker, F. Ghorayeb, and M. Kanj, "Life Experiences, Response Styles and Mental Health among Mothers and Children in Beirut, Lebanon," Social Science Medicine 28, no. 7 (1989): 685-695.
13. D. E. Jacobson, "Types and Timing of Social Support," Journal of Health and Social Behavior 27, no. 3 (1986), 250-264.

14 As cited in R. J. Apfel and B. Simon, "Psychosocial Interventions for Children of War: The Value of a Model of Resiliency," Medicine and Global Survival, <http://www.ippnw/org/ MGS/V3Apfel.html> (accessed October 16, 2005).

15. A. M. Almedom, et al., "Maternal Psychosocial Well-being in Eritrea: Application of Participatory Methods and Tools of Investigation and Analysis in Complex Emergency Settings," Bulletin of the World Health Organization 82, no. 5 (2003): 360-366.

16. Ibid.

17. M. Robinson and S. McKay, A Conference on Girl Mothers in Fighting Forces and Their Post-War Reintegration in Southern and Western Africa, conference report, June 2005, The Rockefeller Foundation Bellagio Center.

18. World Health Organization, Postpartum care of the mother and newborn, report of a Technical Working Group, March 1998, <http://www.who.int/reproductive-health/publications/msm_98_3/postpartum_care_mother_newborn.pdf $>$ (accessed January 16, 2006).

19. T. Field, "Infants of Depressed Mothers," Infant Behavior and Development 18 (1995): 1-13.

20. A. Shah, India: maternal depression stunts babies, Women's Feature Service, April 14, 2003, <http://proquest.umi.com/ pqd web? $\mathrm{did}=81168181 \&$ sid $=8 \& \mathrm{Fmt}=3 \&$ clientid $=15403 \&$ $\mathrm{RQT}=309 \& \mathrm{VName}=\mathrm{PQD}>$ (accessed October 26, 2005).

21. S. Krause, "Progress, Gaps and Challenges Ahead: An Interagency Global Evaluation of Reproductive Health for Refugees and Internally Displaced Persons," Global Health Link 129 (December 2004): 6-7, 18.

22. Jacobson.

23. Ibid.

24. Ibid., 252

25. Almedom et al.

26. Jacobson, 252.

27. Ibid.

28. R. Dybdahl, "Children and Mothers in War: An Outcome Study of Psychosocial Intervention Program," Child Development 72, no. 4 (July/August 2001): 1214-1230.

Bree Akesson is program manager for the Care and Protection of Children in Crisis Affected Countries initiative at Columbia University's Program on Forced Migration and Health at the Mailman School of Public Health. Prior to her current position, she was treatment facilitator for the Child Psychiatric Epidemiology Group at the New York State Psychiatric Institute. She has worked on public health programs in east Africa and the northern Caucasus. She has both a Master of Public Health and a Master of Science in Social Work from Columbia University, and is a licensed master social worker (LMSW). 